\title{
ENFOQUES DE INVESTIGACIÓN EN ARTES Y RECURSOS NARRATIVOS PARA LA ORGANIZACIÓN Y REPRESENTACIÓN DE PROCESOS EN INVESTIGACIÓN ARTÍSTICA
}

Arts research approaches and narrative resources for the organization and representation of processes in artistic research

Nuria Rey Somoza y Rut Martín Hernández

ISSN (imp): 1390-4825

ISSN (e): 2477-9199

Fecha de recepción: 03/09/2020

Fecha de aceptación: 04/19/2020 


\section{Resumen:}

Son varios los modelos de investigación artística planteados desde la academia con el propósito de situar la disciplina como un campo validado a la par de otras áreas de conocimiento. Los fundamentos comunes a estos caracterizan los métodos desde las artes por tres aspectos principales: la transdisciplinaridad, el carácter interpretativo, y la contextualización de prácticas y conocimientos. Sin embargo, la no concreción de metodologías propias de las artes propicia la adopción de mecanismos validados por otras disciplinas para responder al panorama de difusión académica y científica. A partir de una revisión bibliográfica de 60 materiales sobre este tema, se presenta en el artículo un desarrollo sobre modos de investigación en artes y algunas de sus estrategias. Como técnicas y recursos para la evidencia de procesos de investigación en artes, en este artículo se destacan varios que serían útiles para el posicionamiento dentro de la comunidad académico-científica.

\section{Palabras clave:}

Investigación artística, metodología de investigación, práctica artística, enfoque interpretativo, técnicas de investigación.

\section{Abstract:}

There are several models of artistic research suggested in the academy, with the purpose of situating art as a legitimate field alongside other academic area. Common foundations to these characterize arts' methods by three main aspects: transdisciplinarity, interpretative character, and contextualization of practices and knowledge. However, the lack of specific methodologies in arts has led to the adoption of mechanisms validated by other disciplines, to answer to academic and scientific dissemination landscape. Based on a bibliographic review of 60 materials on this subject, this article presents types of research in arts and some of their strategies. As resources for the evidence of research processes in the arts, this article highlights several that would be useful for positioning within the academic-scientific community.

\section{Key Words:}

Art research, research methodology, artistic practice, interpretative approach, research techniques.

\section{Biografía de las autoras:}

Nuria Rey Somoza. Graduada en Bellas Artes y Máster en Educación Artística en Instituciones Sociales y Culturales. Desde 2016, Nuria Rey Somoza (Madrid, España, 1991) desarrolla su doctorado en la Universidad Complutense de Madrid, UCM, Espańa y realiza una estancia en la UCM como Colaboradora Honorífica en el Departamento de Pintura de la Facultad de Bellas Artes. Fue docente y responsable de investigación en la Escuela de Diseńo de la PUCE Sede Esmeraldas. Ha coordinado proyectos de investigación sobre educación artística y cultura digital, teniendo como último resultado la obra colectiva Viralizar la educación: red de experiencias didácticas en torno al meme de Internet.

Rut Martín Hernández. Doctora en Bellas Artes y Magister en Teoría y Práctica de las Artes Contemporáneas por la UCM. Profesora y Secretaria Académica del Departamento de Pintura y Conservación Restauración de la UCM. Ha dirigido el grupo "Arte y Estética" y forma parte de "Prácticas artísticas y formas de conocimiento contemporáneas", "Estética y Filosofía de la Imagen", "ACIS" y de los proyectos I+D "Interacciones del arte en la tecnosfera” e "Imágenes, acción y poder. Agencia icónica y prácticas de la imagen contemporánea”. Su línea principal de investigación es: imágenes artísticas, procesos afectivos y prácticas sociales. 


\section{Introducción y método}

Los planteamientos académicos en investigación artística no cuentan con tanta trayectoria como otras áreas de conocimiento (según Gray y Malins, 1993, no más de 50 años actualmente,), por lo que sus métodos se han ido apropiando de sistemas considerados como válidos para poder integrarse en la estructuración de difusión del conocimiento científico. El presente trabajo expone un proceso de análisis sobre la literatura existente para determinar posibilidades en el diseño de investigación artística desde el plano metodológico. Consiste en una revisión bibliográfica de enfoques y modelos de investigación en artes, que pueda visibilizar $\mathrm{y}$ poner en valor estrategias, instrumentos y procesos desde la experiencia artística. Así, el objetivo es localizar estrategias para la investigación artística, útiles y válidas desde la perspectiva de la forma de producción científicoacadémica contemporánea que a su vez, atiendan a las especificidades de las investigaciones artísticas. El enfoque general de este trabajo es el cualitativo desde el análisis documental, teniendo como materiales de estudio documentos sobre metodologías desde las artes desde 1984 hasta 2019 (total de 60 documentos). ${ }^{2}$

\section{Arte y producción de saberes}

La necesidad de reivindicar unos modos de hacer específicos en torno a la investigación artística surge dentro del ámbito académico. Esta cuestión es relevante en la medida que implica la inserción de este tipo de investigaciones en un contexto ya condicionado por unas lógicas de legitimación tradicionalmente asentadas. Por afinidad con los estudios humanísticos, las investigaciones en artes han sido situadas en relación con los mismos (Wesseling, 2019). En las últimas décadas, esto ha propiciado un espacio para un fructífero debate que también visibiliza los conflictos que surgen en estos procesos de validación. Por otra parte, cabe señalar que el interés en la investigación en artes lleva a abordar estas cuestiones fuera del ámbito académico, transformando en ocasiones, la naturaleza de las propias prácticas artísticas

1 El contenido aquí presentado forma parte del trabajo de investigación doctoral de Nuria Rey Somoza, dirigido y tutorizado por Rut Martín Hernández, desde la Facultad de Bellas Artes de la Universidad Complutense de Madrid, que actualmente se encuentra en proceso.

2 El listado de materiales estudiados se incluye como anexo en una tabla de consulta para ampliar las referencias.
(Cotter, 2019).

Uno de los ejes de este debate se encuentra en la propia definición terminológica, así algunos autores plantean arts-based research (Barone y Eisner, 2006), artsinformed research (Cole, Neilson, Knowels y Luciani, 2004), A/r/tlography (Irwin y de Cosson, 2004) o practicebased research (Candlin, 2000; Frayling, 1997). Para Sullivan (2006) el término con mayor consenso es practicebased research, y para Borgdoff (2010) el más explícito es práctica como investigación. Elo (2019), en este sentido, plantea que investigación artística es un término paraguas que puede abarcar todo tipo de investigaciones en artes, $y$ es el que se ha tomado de referencia en este texto.

Entre otros factores, la dicotomía entre arte y ciencia viene determinada por la sistematización de disciplinas, enmarcando cada una de ellas en posiciones determinadas de producción; sin embargo, comparten en esencia su función como corrientes cuestionadoras y generadoras de conocimiento desde distintas opciones de abordaje de los fenómenos. A pesar de ello, el imaginario colectivo y las reticencias desde el ámbito académico han producido relaciones incómodas entre las dos áreas que, adicionalmente, en muchas ocasiones provoca su no convivencia (Prophet, 2011). Este es el dilema donde se sitúa la investigación artística al intentar integrarse en los parámetros de la producción académica actuales (Sullivan, 2006). Un conflicto que, en todo caso, no ha sido exclusivo del campo de las artes, sino que ya ocurrió desde las ciencias sociales y, por ello, puede ser un antecedente de guía para la validación. En este sentido, el logro de áreas como las ciencias sociales ha sido superar el método científico (entendido como único e inflexible; Gustems, Portela y Calderón, 2017) al concretar sus propios enfoques metodológicos y productivos. Como indica Moraza (2008), la neutralidad del conocimiento está basada en un mito de verdad, una producción y difusión de la verdad asociadas a las áreas científicas al igual que se asociaba el arte a la representación de la belleza como único fin (Sánchez, 2013). Planteamientos que, con la evolución y la colaboración entre disciplinas, desdibuja la idealización del método único en favor de estrategias con capacidad de integración para responder a las particularidades de los fenómenos situados a investigar. Poniendo en valor, de este modo, aspectos para la generación de saberes como la apertura al descubrimiento, la curiosidad, la creativa y el espíritu crítico. La validación, pues, partiría de la aplicación de estos elementos para el desarrollo de procesos de rigor 
(Gray y Malins, 1993; Ramírez, 2013). Estos, para su evaluación, serán transparentes, y replicables (mismo proceso y mismos resultados, asociado a un paradigma positivista) o transferibles (similar proceso y resultados potencialmente variables, asociado a un abordaje interpretativo). Elo (2019) plantea que la investigación artística, más que servir para acumular conocimiento, pone el eje en configurar saberes relacionales.

\section{Factores clave y modelos de investigación artística}

En modelos metodológicos de investigación artística destacan aspectos en primer plano como la subjetividad, la apertura hacia otras disciplinas, y el sentido crítico-interpretativo. La integración de otras áreas al proceso de investigación en artes será contemplada como un ágora donde abordar problemas comunes mediante formatos híbridos transdisciplinares (Nowotny, 2006). En este tipo de escenarios, es necesario dar cabida a las subjetividades de los agentes implicados, lo que presupone que otros elementos como la experiencia, el posicionamiento, el contexto y el conocimiento corporeizado son factores que deben reconocerse como parte del proceso.

Previamente se mencionaba que las metodologías del arte pueden seguir a las sociales y su enfoque cualitativo hacia su legitimación, donde los factores expuestos (subjetividad, experiencia, transdisciplinaridad, posicionamiento) son analizables sin necesidad de categorizar herméticamente los resultados. Apropiarse, de este modo, de enfoques interpretativos (abordaje de significados-experiencias de las prácticas contextualizadas) o socio-críticos (implicación participante del investigador con espíritu transformador). El carácter interpretativo de las prácticas y experiencias artísticas es constante durante todo el proceso, y a su vez estas prácticas potencian múltiples interpretaciones (Borgdoff, 2010). No deberían, por tanto, obviarse esas posibilidades interpretativas de análisis, reflexión y crítica a la hora de plantear recorridos y resultados de investigación artística. El rigor y la coherencia en estos procesos, con mayor flexibilidad y fases interpretativas múltiples, se sostienen en factores como la contextualización (no solo física, sino discursiva y sensitiva) y el conocimiento situado (Haraway, 1995). En esta línea, Borgdoff (2010) expone que la investigación en artes recoge elementos propios de las prácticas artísticas como el estudio del objeto (tangible o intangible), la importancia del acto procesual, y la relación con agentes y contextos que participan de la producción.

Sullivan (2006) estudia la investigación en relación con los actos que ésta implica, ayudando así a identificar el tipo de saberes que circulan. Determina tres elementos principales que participan en los estudios procesuales y prácticas culturales: estructura, agencia y acción. En función de los mismos, presenta cuatro actos: (1) teoréticos (operaciones conceptuales complejas), (2) formativos (comprensión a partir de la experimentación y el conocimiento performativo, equiparable a la observación y la confirmación empírica), (3) interpretativos (dinámicas creativas, saberes de una investigación-creación) y (4) críticos (potencial transformador de lo artístico).

Para ubicar de qué manera esos factores se definen en modos concretos de metodologías artísticas de investigación, se presentan en este momento algunos planteamientos propuestos por distintos autores, los cuales comparten las características generales que señala Insúa (2013): trato de gran variedad de temáticas, empleo de metodologías híbridas, y desarrollos epistemológicos plurales. En primer lugar, Frayling (1993) presenta una categorización de tres vías de investigación artística (basada en la práctica), donde las opciones de abordaje son: (1) investigación dentro del arte, (2) investigación para el arte y (3) investigación a través del arte. Borgdoff (2010), partiendo del modelo anterior, plantea estas vertientes: (1) investigación sobre las artes (siendo un planteamiento de investigación aplicada), (2) investigación para las artes (donde la práctica es el proceso de investigación y resultados en sí mismos), y (3) investigación en artes (en la que el propio proceso creativo genera y aglomera los conocimientos teórico-prácticos). Elkins (2005), por su parte, replantea estas corrientes con otros tres enfoques: la investigación artística puede (1) informar sobre el arte o el resultado artística, aproximándose a áreas como la historia o la crítica, (2) equiparar producto artístico e investigativo en un abordaje conjunto, o (3) comprender la práctica artística e investigativa como una misma acción. De estos tres últimos, Sánchez (2013) matiza que el primero se corresponde con una investigación sobre o con las artes, mientras que los otros responden a procesos de investigación en artes, que en su opinión es el abordaje más interesante para la legitimación de instrumentos y recursos metodológicos propios. 


\section{Estrategias e instrumentos gráfico-metodológicos}

A partir de las características descritas anteriormente, un punto de partida para el ejercicio en investigación artística es defender las cualidades representativas de este campo (la cultura visual y la experiencia estética) para interpretar los afectos, situaciones y cruces interdisciplinarios que se producen en el proceso artístico. Cabe destacar, por otro lado, el planteamiento de Fernández-Polanco (2014, p. 218) para "pensar con las imágenes", esto es, comprender las imágenes no solo como materiales que analizar, sino como representaciones con sus propias narrativas (interpretar desde la posición de investigador conjuntamente con ellas y con los discursos que encierran). Así, las imágenes funcionan como resultados, método y proceso de análisis en una investigación, siendo representaciones productoras de conocimiento. Son así, las imágenes fotográficas, los dibujos, bocetos, pinturas, imagen en movimiento, las que posibilitan, por un lado, un modo de documentar procesos y por otro, un corpus de imágenes que adquiere un carácter medial entre la práctica y la investigación. Los modos de hacer ensayados en las prácticas artísticas suponen un campo de pruebas de aquellos instrumentos que pueden llegar a insertarse dentro de las investigaciones artísticas, en un camino en el que las metodologías de investigación acaban visibilizando hasta qué punto se nutren de la propia práctica. Con este fundamento, son varias las técnicas de investigación con recorrido desde otras áreas que pueden ser adaptadas a las necesidades de metodologías propias. Se pueden mencionar, entre ellas, estrategias como el archivo, recurso presente en la historia del arte no solo como sistema de ordenamiento, sino como formato de creación artística (Guasch, 2011). De la misma manera, caben en estas metodologías técnicas como la investigación-acción participativa, que está relacionada con el arte de contexto (García-Cano, 2013), así como las historias de vida que recupera la esencia del estudio etnográfico hacia planteamientos de autoetnografía (Insúa, 2013), que necesariamente incluye en el proceso la subjetividad del investigador participante para las interpretaciones y construcción de significados visuales. Por otro lado, y aproximándose a la idea de cuaderno de bitácora, una estrategia de documentación interpretativa es el diario de investigación, en el que caben notas, pero también otras formas de representación de los procesos. En este sentido, Gray y Malins (1993) proponen desarrollar un diario que vaya recogiendo las observaciones del estudio.
¿Qué recursos pueden ser de utilidad en un análisis de datos en investigación artística para situar los procesos dentro de los marcos de producción académica y científica? Se han localizado varios gracias a la revisión de la literatura, que tienen como punto común la prioridad del componente analítico-visual para la presentación de los procesos y guardarán, por ello, patrones estéticos relacionados con las artes visuales y el diseño: la organización infográfica y el visual thinking. Estos permiten destinar la construcción visual a la recogida y exposición de subjetividades e interacciones, posibilitando además representaciones de procesos no-lineales, rizomáticos, que se expanden, modifican e interrelacionan según el propio proceso avanza.

El primero de ellos sería el uso de mapas conceptuales para la definición o categorización de ideas, acciones, vínculo, juicios, símbolos, flujos de movimiento y de poder (Ribas, 2017). Estos pueden adaptarse a las necesidades de cada estudio y presentarse desde sus formas más populares (por ejemplo, en forma word cloud), o insertando distintos elementos para expresar mayor complejidad. Enlazando con esta manera de representar se localiza el segundo recurso: el pensamiento diagramático y sus manifestaciones visuales, donde el diagrama funciona como "método o herramienta que propicia nuevos imaginarios, al mismo tiempo que analiza y traduce" y abre posibilidades creativas para reinterpretar los análisis que contiene (Del Pozo, 2014, p. 321). Con estas dos herramientas se contempla también el uso de cartografías críticas que puedan visibilizar y responder a problemas de investigación en artes (Perales, 2010) desde lo relacional, lo experiencial, y lo gráfico. Pudiendo convertirse estos recursos en investigaciones en sí mismas (Ribas, 2017) o en mecanismos de teorización de realidades y fenómenos (Guattari, 2006). El tercer y último recurso que se localiza con esta intención es la relatoría gráfica, que consiste en producir imágenes capaces de captar las energías, flujos, ritmos y actividades del proceso, con la particularidad de ser materiales generados mientras transcurre la acción. Siendo, de este modo, una herramienta metodológica de comunicación de procesos a partir de registros gráficos multiformato que construyen narraciones no-lineales (Boserman, 2014).

\section{Conclusiones}

La ausencia o falta de concreción de metodologías propias desde las artes, y su consecuente 
adopción de estrategias traducidas desde otras disciplinas, puede entenderse como una desventaja, pero también como una oportunidad para la búsqueda de escenarios eficaces que respondan a potencialidades de la investigación en artes, e intentar así desde este lugar el posicionamiento de mecanismos propios dentro del ámbito general de producción en investigación. El trabajo con otras disciplinas es un modo de valorizar los saberes ofreciendo opciones metodológicas diversas que destaquen la cualidad, la experiencia, la sensibilidad y la crítica, y adaptando los recursos de investigación y análisis a los fenómenos e inquietudes del arte. Será determinante para ello la presentación explícita de cómo funcionan las claves en el proceso interpretativo de investigación.

Gracias a la revisión de la literatura se pueden concretar estrategias y técnicas que funcionan de manera coherente desde un enfoque artístico, esforzándose por determinar métodos para combatir imaginarios que interpretan los procesos como poco rigurosos o ambiguos. Entre ellas, como técnicas se han destacado en este texto el arte de contexto, la etnografía de enfoque artístico, o la auto-etnografía. Como instrumentos para el análisis y visualización de resultados se han presentado como herramientas el diario gráfico y las representaciones desde el pensamiento visual, entre las que destacan la estructura diagramática, mapa o cartografía conceptual, y relatoría gráfica.

\section{Referencias}

Barone, T. y Eisner, E. (2006). Arts-Based Educational Research. En Green, J., Grego, C. y Belmore, P. (Eds.). Handbook of Complementary Methods in Educacional Research, pp. 95-109. Mahwah, New Jersey: AERA.

Borgdorff, H. (2010). El debate de la investigación en las artes. Cairon: revista de ciencias de la danza, núm. 13, pp. 25-46.

Boserman, C. (2014). Entre grafos y bits. Obra digital, núm. 6, pp. 8-23.

Candlin, F. (2000). Practice-based doctorates and questions of academic legitimacy. Journal of Art and Desing Education, 19 (1), pp. 96-101. de las prácticas artísticas para la comunidad académica,

(2004). Provoked by art: Theorizing arts-informed research. Halifax, Nova Scotia: Backlong Books.

Cotter, L. (Ed.) (2019). Reclaiming Artistic Research. Berlin: Hatje Cantz Verlag.

Del Pozo, D. (2014). Dispositivos artísticos de afectación. Las economias afectivas en las prácticas artísticas actuales (Tesis Doctoral). Madrid, Universidad Complutense de Madrid.

Elkins, J. (2005). The Three Configurations of PracticeBased PhDs. En Elkins, J. (Ed). Printed Project, ISSUE 4: The New PhD in Studio Art, pp. 7-19. Dublin: Arts Council.

Elo, M. (2019). Paradojas de la investigación artística. En Sixto, R. (Ed.) Piscina. Investigación y práctica artística. Maneras y ejercicios,pp. 177-192. Bilbao: Ediciones laSIA.

Fernández-Polanco, A. (Ed.) (2014). Pensar la imagen/ Pensar con las imágenes. Madrid: Editorial Delirio S.L.

Frayling, C. (1997). Practice-based doctorates in the creative and performing arts and design. Lichfield, IK: UK Council for Graduate Educationan.

Frayling, C. (1993). Research in art and design. Royal College of Art Research Papers series 1(1). London: Royal College of Art.

García-Cano, M. (2013). Arte, contexto y participación. El hospital como espacio artístico (Tesis Doctoral). Universidad Complutense de Madrid, Madrid.

Gray, C. y Malins, J. (1993). Procedimientos/Metodología de Investigación para Artistas y Diseñadores (documento en línea). Disponible en http:// carolegray.net/researchpapers.html

Guasch, A. (2011). Arte y archivo 1920-2010: Genealogías, tipologias y discontinuidades. Madrid: Akal.

Guattari, F. (2006). Anti-Oedipus Papers. Nueva York: Semiotext(e).

Gustems, J., Portela, A. y Calderón, C. (2017). Aproximaciones metodológicas a la investigación en artes. Artseduca, núm. 17, pp. 79-95.

Cole, A. L., Neilson, L., Knowels, J. G. y Luciani, T. Haraway, D. J. (1995). Ciencia, cyborgs y mujeres. Madrid: 
Ediciones Cátedra S.A.

Insúa, L. (2013). Encuentros dobles. De la investigación artística y sus mecanismos de validación. En Blasco, S. (Ed.) Investigación artística $y$ universidad: materiales para un debate, pp. 4361. Madrid: Ediciones Asimétricas.

Irwin, R., y de Consson, A. (Eds.) (2004). Artography: rendering self-through arts-based living enquiry. Vancouver: Pacific Educational Press.

Moraza, J. L. (2008). Aporías de la investigación (trans, sobre, so, sin, según, por, para, hasta, hacia, desde, de, contra, con, cabe, bajo, ante, en) arte. Notas sobre el sabcer. En De Laiglesia, J. F., Rodríguez, M. y Fuentes, S. (Eds.) Notas para una investigación artística, pp. 35-73. Vigo: Servicio de publicaciones de la Universidad de Vigo.

Nowotny, H. (2006). The potencial of transdisciplinarity (artículo en línea). Disponible en http://www. helga-nowotny.eu/texts.php

Perales, V. (2010). Cartografías desde la perspectiva artística. Diseñar, trazar y navegar la contemporaneidad. Arte, Individuo y Sociedad, 22, (2), pp. 83-90.

Prophet, J. (2011). El artista en el laboratorio: una cooperación razonablemente traicionera. Artnodes. Revista de Arte, Ciencia y Tecnología, núm. 11, pp. 39-44.

Ramírez, J. (2013). ¡A las armas! Herramientas y rigor para la investigación en arte. En Blasco, S. (Ed.) Investigación artística y universidad: materiales para un debate, pp. 63-71. Madrid: Ediciones Asimétricas.

Ribas, C. (2017). Cartography as Research Process: A Visual Essay. En Hwang, S. y de Roulet, P. Bibliography (choréme) $=$ OAR Issue 1. ORA: The Oxford Artistic and Practice Based Research Platform Issue 1.

Sánchez, J. A. (2013). In-definiciones. El campo abierto de la investigación en artes. Artes, la revista, 12 (19), pp. 36-51.

Sullivan, G. (2006). Research Acts in Art Practice. Studies in Art Education. A journal of Issues and Reseach, 48 (1), pp. 19-35.

Wesseling J. (2019). Investigación artística en la Academy of Creative and Performing Arts, Universidad de Leiden. En Sixto, R. (Ed.). Piscina. Investigación y práctica artística. Maneras y ejercicios, pp.157165. Bilbao: Ediciones laSIA. 
Anexo: Listado de materiales bibliográficos de la revisión

\begin{tabular}{|c|c|c|c|c|c|}
\hline$\#$ & Año & Autores & Título & Tipo & Localización \\
\hline 1 & 1984 & Cornock & $\begin{array}{l}\text { Towards a Methodology for Students } \\
\text { of Fine Arts }\end{array}$ & $\begin{array}{l}\text { Artículo en } \\
\text { revista }\end{array}$ & $\begin{array}{l}\text { Journal of Art \& Design Education, } \\
2(1) \text {, pp.81-99 }\end{array}$ \\
\hline 2 & 1992 & Guattari & $\begin{array}{l}\text { Chaosmosis: An Ethico-Aesthetic } \\
\text { Paradigm }\end{array}$ & Libro & $\begin{array}{l}\text { Bloomington: Indiana University } \\
\text { Press }\end{array}$ \\
\hline 3 & 1993 & Feyerabend & Against Method & Libro & Londres: Verso \\
\hline 4 & 1993 & Frayling & $\begin{array}{l}\text { Research in art and design. Royal } \\
\text { College of Art Research Papers series } \\
1(1) \text {. }\end{array}$ & Libro & London: Royal College of Art \\
\hline 5 & 1993 & Gray y Malins & $\begin{array}{l}\text { Procedimientos/Metodología } \\
\text { de Investigación para Artistas y } \\
\text { Diseńadores }\end{array}$ & $\begin{array}{l}\text { Artículo en } \\
\text { línea }\end{array}$ & $\begin{array}{l}\text { h t t p : / / c a rol e gray.net / } \\
\text { researchpapers.html }\end{array}$ \\
\hline 6 & 1997 & $\begin{array}{l}\text { Slaughter y } \\
\text { Leslie }\end{array}$ & $\begin{array}{l}\text { Academic capitalism: politics, policies } \\
\text { and the entrepreneurial university }\end{array}$ & Libro & $\begin{array}{l}\text { Baltimore: The John Hopkins } \\
\text { University Press }\end{array}$ \\
\hline 7 & 1997 & Frayling & $\begin{array}{l}\text { Practice-based doctorates in the } \\
\text { creative and performing arts and } \\
\text { design }\end{array}$ & Libro & $\begin{array}{l}\text { Lichfield, IK: UK Council for } \\
\text { Graduate Educationan }\end{array}$ \\
\hline 8 & 2000 & Candlin & $\begin{array}{l}\text { Practice-based doctorates and } \\
\text { questions of academic legitimacy }\end{array}$ & $\begin{array}{l}\text { Artículo } \\
\text { revista }\end{array}$ & $\begin{array}{l}\text { Journal of Art and Desing } \\
\text { Education, } 19 \text { (1), pp. 96-101 }\end{array}$ \\
\hline 9 & 2003 & Ibarra & \begin{tabular}{lll} 
Capitalismo & \multicolumn{2}{l}{ académico $\quad$ y } \\
globalización: & la universidad \\
reinventada & & \\
\end{tabular} & $\begin{array}{l}\text { Artículo } \\
\text { revista }\end{array}$ & $\begin{array}{l}\text { Educação \& Sociedade, } 24 \text { (84), } \\
\text { pp. 1059-1067 }\end{array}$ \\
\hline 10 & 2004 & Eisner & $\begin{array}{l}\text { El arte y la creación de la mente: } \\
\text { el papel de las artes visuales en la } \\
\text { transformación de la conciencia }\end{array}$ & Libro & Barcelona: Paidós \\
\hline 11 & 2004 & $\begin{array}{l}\text { Irwin y de } \\
\text { Consson }\end{array}$ & $\begin{array}{l}\text { Artography: rendering self-through } \\
\text { arts-based living enquiry }\end{array}$ & Libro & $\begin{array}{l}\text { Vancouver: Pacific Educational } \\
\text { Press }\end{array}$ \\
\hline 12 & 2004 & $\begin{array}{l}\text { Weber y } \\
\text { Mitchell }\end{array}$ & $\begin{array}{l}\text { Visual artistic modes of representation } \\
\text { for self-study }\end{array}$ & $\begin{array}{l}\text { Capítulo de } \\
\text { libro }\end{array}$ & $\begin{array}{l}\text { En Loughran, J. J., Hamilton, M. } \\
\text { L., LaBoskey, V. K. y Russell, T. } \\
\text { (Eds.) The international handbook } \\
\text { of self-study of teaching and teacher } \\
\text { education practices pp. 979-1037. } \\
\text { Dordrecht: Kluwer Academic. }\end{array}$ \\
\hline 13 & 2004 & $\begin{array}{l}\text { Johnson y } \\
\text { Onwuegbuzie }\end{array}$ & $\begin{array}{l}\text { Mixed methods research: A research } \\
\text { paradigm whose time has come }\end{array}$ & $\begin{array}{l}\text { Artículo en } \\
\text { revista }\end{array}$ & $\begin{array}{l}\text { Educational Researcher, } 33 \text { (7), } \\
\text { pp. 14-26 }\end{array}$ \\
\hline 14 & 2004 & $\begin{array}{l}\text { Cole, Neilson, } \\
\text { Knowels y } \\
\text { Luciani } \\
\end{array}$ & $\begin{array}{l}\text { Provoked by art: Theorizing arts- } \\
\text { informed research }\end{array}$ & Libro & $\begin{array}{l}\text { Halifax, Nova Scotia: Backlong } \\
\text { Books }\end{array}$ \\
\hline 15 & 2005 & Elkins & $\begin{array}{l}\text { The Three Configurations of Practice- } \\
\text { Based PhDs }\end{array}$ & $\begin{array}{l}\text { Capítulo } \\
\text { libro }\end{array}$ & $\begin{array}{l}\text { En Elkins, J. (Ed). En Printed } \\
\text { Project, ISSUE 4: The New PhD in } \\
\text { Studio Art pp. 7-19. Dublin: Arts } \\
\text { Council. }\end{array}$ \\
\hline 16 & 2005 & Huss y Cwikel & $\begin{array}{l}\text { Researching creations: Applying arts- } \\
\text { based research to Bedouin women's } \\
\text { drawings }\end{array}$ & $\begin{array}{l}\text { Artículo } \\
\text { revista }\end{array}$ & $\begin{array}{l}\text { International Journal of Qualitative } \\
\text { Methods, } 4 \text { (4). }\end{array}$ \\
\hline
\end{tabular}




\begin{tabular}{|c|c|c|c|c|c|}
\hline 17 & 2006 & Barone y Eisner & Arts-Based Educational Research & $\begin{array}{l}\text { Capítulo de } \\
\text { libro }\end{array}$ & $\begin{array}{l}\text { En Green, J., Grego, C. y } \\
\text { Belmore, P. (Eds.). Handbook } \\
\text { of Complementary Methods in } \\
\text { Educacional Research pp.95-109. } \\
\text { Mahwah, New Jersey: AERA }\end{array}$ \\
\hline 18 & 2006 & Guattari & Anti-Oedipus Papers & Libro & Nueva York: Semiotext(e) \\
\hline 19 & 2006 & Nowotny & The potencial of transdisciplinarity & $\begin{array}{l}\text { Artículo en } \\
\text { línea }\end{array}$ & $\begin{array}{l}\text { http://www.helga-nowotny.eu/ } \\
\text { texts.php }\end{array}$ \\
\hline 20 & 2006 & Sullivan & Research Acts in Art Practice & \begin{tabular}{|l|}
$\begin{array}{l}\text { Artículo en } \\
\text { revista }\end{array}$ \\
\end{tabular} & $\begin{array}{l}\text { Studies in Art Education. A Journal } \\
\text { of Issues and Research, } 48 \text { (1). }\end{array}$ \\
\hline 21 & 2008 & Hernández & $\begin{array}{l}\text { La investigación basada en las } \\
\text { artes. Propuestas para repensar la } \\
\text { investigación en educación }\end{array}$ & $\begin{array}{l}\text { Artículo en } \\
\text { revista }\end{array}$ & $\begin{array}{l}\text { Educatio Siglo XXI, 26, pp. 85- } \\
118\end{array}$ \\
\hline 22 & 2008 & $\begin{array}{l}\text { De Laiglesia, } \\
\text { Rodríguez y } \\
\text { Fuentes }\end{array}$ & Notas para una investigación artística & Libro & $\begin{array}{l}\text { Vigo: Servicio de publicaciones de } \\
\text { la Universidad de Vigo }\end{array}$ \\
\hline 23 & 2008 & $\begin{array}{l}\text { National Art } \\
\text { Education } \\
\text { Association }\end{array}$ & $\begin{array}{l}\text { Creating a Visual Arts Education } \\
\text { Research Agenda for the 21st } \\
\text { Century: Encouraging Individual and } \\
\text { Collaborative Research }\end{array}$ & $\begin{array}{l}\text { Artículo } \\
\text { línea }\end{array}$ & $\begin{array}{l}\text { https://www.arteducators.org/ } \\
\text { research/articles/94-creating-a- } \\
\text { visual-arts-education-research- } \\
\text { agenda-for-the-21st-century- } \\
\text { encouraging-individual-and- } \\
\text { collaborative-research }\end{array}$ \\
\hline 24 & 2009 & Vujanovic & Research (Experiment > Laboratory) & \begin{tabular}{|l|} 
Artículo en \\
línea
\end{tabular} & $\begin{array}{l}\text { http://www.deschoolingclassroom. } \\
\text { tkh-generator.net/2009/05/17/ }\end{array}$ \\
\hline 25 & 2010 & Borgdorff & $\begin{array}{l}\text { El debate de la investigación en las } \\
\text { artes }\end{array}$ & \begin{tabular}{|l|}
$\begin{array}{l}\text { Artículo en } \\
\text { revista }\end{array}$ \\
\end{tabular} & $\begin{array}{l}\text { Cairon: revista de ciencias de la } \\
\text { danza, } 13 \text {, pp. } 25-46 .\end{array}$ \\
\hline 26 & 2010 & $\begin{array}{l}\text { Cantalozella i } \\
\text { Planas }\end{array}$ & $\begin{array}{l}\text { Frente al reto de la investigación } \\
\text { artística. Algunas consideraciones en } \\
\text { torno a la creación y su contexto }\end{array}$ & $\begin{array}{l}\text { Artículo en } \\
\text { revista }\end{array}$ & Observar, 4, pp. 45-56 \\
\hline 27 & 2010 & Evers & $\begin{array}{l}\text { Los procesos y el arte más allá de la } \\
\text { representación }\end{array}$ & $\begin{array}{l}\text { Capítulo de } \\
\text { libro }\end{array}$ & $\begin{array}{l}\text { En LABoral Centro de Arte y } \\
\text { Creación Industrial. El proceso } \\
\text { como paradigma. Arte en } \\
\text { desarrollo, movimiento y cambio } \\
\text { pp. 145-154. LABoral Centro } \\
\text { de Arte y Creación Industrial y } \\
\text { Fundación Telefónica. }\end{array}$ \\
\hline 28 & 2010 & Gottlieb & Los signos vitales del arte procesual & $\begin{array}{l}\text { Capítulo de } \\
\text { libro }\end{array}$ & $\begin{array}{l}\text { En LABoral Centro de Arte y } \\
\text { Creación Industrial. El proceso } \\
\text { como paradigma. Arte en } \\
\text { desarrollo, movimiento y cambio } \\
\text { pp.123-130. LABoral Centro } \\
\text { de Arte y Creación Industrial y } \\
\text { Fundación Telefónica. }\end{array}$ \\
\hline 29 & 2010 & Martínez & $\begin{array}{l}\text { Felicidad clandestina. ¿Qué queremos } \\
\text { decir con investigación artística? }\end{array}$ & \begin{tabular}{|l|}
$\begin{array}{l}\text { Artículo en } \\
\text { revista }\end{array}$ \\
\end{tabular} & Index, 0 , pp. 10-13 \\
\hline 30 & 2010 & Perales & $\begin{array}{l}\text { Cartografías desde la perspectiva } \\
\text { artística. Diseñar, trazar y navegar la } \\
\text { contemporaneidad }\end{array}$ & $\begin{array}{l}\text { Artículo en } \\
\text { revista }\end{array}$ & $\begin{array}{l}\text { Arte, Individuo y Sociedad, 22, } \\
\text { (2), pp. 83-90 }\end{array}$ \\
\hline
\end{tabular}




\begin{tabular}{|c|c|c|c|c|c|}
\hline 31 & 2010 & Steyerl & $\begin{array}{l}\text { ¿Una estética de la resistencia? } \\
\text { La investigación artística como } \\
\text { disciplina y conflicto }\end{array}$ & $\begin{array}{l}\text { Artículo en } \\
\text { línea }\end{array}$ & $\begin{array}{l}\text { http://eipcp.net/transversal/0311/ } \\
\text { steyerl/es }\end{array}$ \\
\hline 32 & 2011 & García-Varas & Filosofía de la imagen & Libro & $\begin{array}{l}\text { Salamanca: Ediciones Universidad } \\
\text { de Salamanca }\end{array}$ \\
\hline 33 & 2011 & Guasch & $\begin{array}{l}\text { Arteyarchivo 1920-2010: Genealogías, } \\
\text { tipologías y discontinuidades. }\end{array}$ & Libro & Madrid: Akal \\
\hline 34 & 2011 & Alsina & $\begin{array}{l}\text { Diez años cartografiando las } \\
\text { interrelaciones entre arte, ciencia y } \\
\text { tecnología }\end{array}$ & $\begin{array}{l}\text { Artículo en } \\
\text { revista }\end{array}$ & $\begin{array}{l}\text { Artnodes. Revista de Arte, Ciencia } \\
\text { y Tecnología, 11, pp. } 2-3\end{array}$ \\
\hline 35 & 2011 & Galanter & $\begin{array}{l}\text { Entre dos fuegos: el arte-ciencia y la } \\
\text { guerra entre ciencia y humanidades }\end{array}$ & $\begin{array}{l}\text { Artículo en } \\
\text { revista }\end{array}$ & $\begin{array}{l}\text { Artnodes. Revista de Arte, Ciencia } \\
\text { y Tecnología, 11, pp. 33-38 }\end{array}$ \\
\hline 36 & 2011 & Thomas & $\begin{array}{l}\text { Estrategias transdisciplinarias para las } \\
\text { bellas artes y la ciencia }\end{array}$ & $\begin{array}{l}\text { Artículo en } \\
\text { revista }\end{array}$ & $\begin{array}{l}\text { Artnodes. Revista de Arte, Ciencia } \\
\text { y Tecnología, 11, pp. 56-61 }\end{array}$ \\
\hline 37 & 2011 & Marín & $\begin{array}{l}\text { La investigación en Educación } \\
\text { Artística }\end{array}$ & $\begin{array}{l}\text { Artículo en } \\
\text { revista }\end{array}$ & $\begin{array}{l}\text { Educatio Siglo XXI, } 29 \text { (1), } 211- \\
230\end{array}$ \\
\hline 38 & 2011 & Prophet & $\begin{array}{l}\text { El artista en el laboratorio: una } \\
\text { cooperación } \\
\text { traicionera }\end{array}$ & $\begin{array}{l}\text { Artículo en } \\
\text { revista }\end{array}$ & $\begin{array}{l}\text { Artnodes. Revista de Arte, Ciencia } \\
\text { y Tecnología, 11, pp. 39-44 }\end{array}$ \\
\hline 39 & 2011 & Rolnik & $\begin{array}{l}\text { Cartografia Sentimental: } \\
\text { Transformaçoes Comtemporâneas do } \\
\text { Desejo }\end{array}$ & Libro & Porto Alegre: Editora da UFRGS \\
\hline 40 & 2012 & $\begin{array}{l}\text { Estévez y De } \\
\text { Santa Ana }\end{array}$ & Memorias y olvidos del archivo & Libro & Madrid: Editorial Lampreave \\
\hline 41 & 2012 & $\begin{array}{l}\text { Hernández y } \\
\text { Aguirre }\end{array}$ & $\begin{array}{l}\text { Investigación en las Artes y la Cultura } \\
\text { Visual }\end{array}$ & Libro & $\begin{array}{lll}\text { Barcelona: Universidad de } \\
\text { Barcelona }\end{array}$ \\
\hline 42 & 2013 & Blasco & $\begin{array}{l}\text { Investigación artística y universidad: } \\
\text { materiales para un debate }\end{array}$ & Libro & Madrid: Ediciones Asimétricas \\
\hline 43 & 2013 & Munárriz & $\begin{array}{l}\text { Investigación y tesis doctoral en Bellas } \\
\text { Artes }\end{array}$ & $\begin{array}{l}\text { Artículo en } \\
\text { línea }\end{array}$ & http://eprints.ucm.es/23022/ \\
\hline 44 & 2013 & Risier y Ares & $\begin{array}{l}\text { Iconoclasistas. Manual de mapeo } \\
\text { colectivo: recursos cartográficos } \\
\text { críticos para procesos territoriales de } \\
\text { creación colaborativa }\end{array}$ & Libro & Buenos Aires: Tinta Limón \\
\hline 45 & 2013 & Sánchez & $\begin{array}{l}\text { In-definiciones. El campo abierto de } \\
\text { la investigación en artes }\end{array}$ & $\begin{array}{l}\text { Artículo en } \\
\text { revista }\end{array}$ & Artes, la revista, 12 (19), pp. 36-51 \\
\hline 46 & 2013 & Villar & $\begin{array}{l}\text { Procesos artísticos en laboratorios: ¿los } \\
\text { medialabs un nuevo espacio para la } \\
\text { educación artística? }\end{array}$ & Tesis doctoral & $\begin{array}{lll}\text { Valladolid, } & \text { Universidad } \\
\text { Valladolid } & \end{array}$ \\
\hline 47 & 2014 & Boserman & Entre grafos y bits & $\begin{array}{l}\text { Artículo en } \\
\text { revista }\end{array}$ & Obra digital, 6, pp. 8-23 \\
\hline 48 & 2014 & Creswell & $\begin{array}{ll}\text { Research design: qualitative, } \\
\text { quantitative and mixed methods } \\
\text { approaches }\end{array}$ & Libro & California: SAGE \\
\hline 49 & 2014 & Del Pozo & $\begin{array}{l}\text { Dispositivos artísticos de afectación. } \\
\text { Las economías afectivas en las prácticas } \\
\text { artísticas actuales }\end{array}$ & Tesis doctoral & $\begin{array}{l}\text { Madrid, Universidad Complutense } \\
\text { de Madrid }\end{array}$ \\
\hline
\end{tabular}




\begin{tabular}{|c|c|c|c|c|c|}
\hline 50 & 2014 & $\begin{array}{l}\text { Fernández- } \\
\text { Polanco }\end{array}$ & $\begin{array}{l}\text { Pensar la imagen/Pensar con las } \\
\text { imágenes }\end{array}$ & Libro & Madrid: Editorial Delirio S.L. \\
\hline 51 & 2015 & $\begin{array}{l}\text { Art Matters y } \\
\text { UOC }\end{array}$ & $\begin{array}{l}\text { Ciclo de entrevistas a profesionales de } \\
\text { la escena artística contemporánea }\end{array}$ & $\begin{array}{l}\text { Entrevistas en } \\
\text { línea }\end{array}$ & $\begin{array}{l}\text { https://www.youtube.com/channel/ } \\
\text { UC35NNnXFVYP7bTYRlzVJLcw }\end{array}$ \\
\hline 52 & 2015 & $\begin{array}{l}\text { Collados- } \\
\text { Alcaide }\end{array}$ & $\begin{array}{l}\text { Laboratorios artísticos colaborativos. } \\
\text { Espacios transfronterizos de } \\
\text { producción cultural }\end{array}$ & $\begin{array}{l}\text { Artículo en } \\
\text { línea }\end{array}$ & $\begin{array}{l}\text { Arte, Individuo y Sociedad, } 27 \text { (1), } \\
\text { pp. 45-64 }\end{array}$ \\
\hline 53 & 2015 & Marín & $\begin{array}{l}\text { Investigación en educación artística: } \\
\text { temas, métodos y técnicas de } \\
\text { indagación sobre el aprendizaje y } \\
\text { la enseńanza de las artes y culturas } \\
\text { visuales }\end{array}$ & Libro & Granada: Universidad de Granada \\
\hline 54 & 2015 & Villar & $\begin{array}{l}\text { Procesos artísticos en laboratorios: } \\
\text { génesis y perspectivas }\end{array}$ & $\begin{array}{l}\text { Artículo en } \\
\text { línea }\end{array}$ & $\begin{array}{l}\text { Universum. Revista de } \\
\text { Humanidades y Ciencias Sociales, } \\
30 \text { (1), pp. 277-292 }\end{array}$ \\
\hline 55 & 2015 & Yustas & $\begin{array}{l}\text { Conocimiento situado y epistemología } \\
\text { feminista en la investigación en arte. De } \\
\text { cómo defender en una comunicación } \\
\text { académica los conflictos específicos } \\
\text { del uso de la enunciación erudita en la } \\
\text { investigación en arte }\end{array}$ & $\begin{array}{l}\text { Comunicación } \\
\text { en congreso }\end{array}$ & $\begin{array}{l}\text { II Congreso Internacional de } \\
\text { Investigación en Artes Visuales } \\
\text { I<real I virtual }>\text { I ANIAV 2015, } \\
\text { Universitat Politecnica de Valencia }\end{array}$ \\
\hline 56 & 2017 & $\begin{array}{l}\text { Gustems, } \\
\text { Portela, y } \\
\text { Calderón }\end{array}$ & $\begin{array}{l}\text { Aproximaciones metodológicas a la } \\
\text { investigación en artes }\end{array}$ & $\begin{array}{l}\text { Artículo en } \\
\text { revista }\end{array}$ & Artseduca, 17, pp. 79-95 \\
\hline 57 & 2017 & $\begin{array}{l}\text { Kaila, Seppä y } \\
\text { Slager }\end{array}$ & $\begin{array}{l}\text { Futures of Artistic Research: At the } \\
\text { Intersection of Utopia, Academia and } \\
\text { Power }\end{array}$ & Libro & $\begin{array}{l}\text { Helsinki: Academy of Fine Arts at } \\
\text { the University of the Arts Helsinki }\end{array}$ \\
\hline 58 & 2017 & Ribas & $\begin{array}{l}\text { Cartography as Research Process: A } \\
\text { Visual Essay }\end{array}$ & $\begin{array}{l}\text { Capítulo de } \\
\text { libro }\end{array}$ & $\begin{array}{l}\text { En Hwang, S. y de Roulet, P. } \\
\text { Bibliography (choréme)= OAR } \\
\text { Issue 1. ORA: The Oxford Artistic } \\
\text { and Practice Based Research } \\
\text { Platform Issue 1 }\end{array}$ \\
\hline 59 & 2019 & Sixto & $\begin{array}{l}\text { Piscina. Investigación y práctica } \\
\text { artística. Maneras y ejercicios }\end{array}$ & Libro & Bilbao: Ediciones laSIA \\
\hline 60 & 2019 & Cotter & Reclaiming Artistic Research & Libro & Berlin: Hatje Cantz Verlag \\
\hline
\end{tabular}

